\title{
ON AMPULLARY TISSUE IN THE LARVA OF POL YCLINUM AURANTIUM MILNE EDWARDS
}

\author{
By D. B. Carlisle, M.A. \\ From the Plymouth Laboratory
}

(Text-fig. I)

The larva of the compound ascidian Polyclinum aurantium Milne Edwards (I842) has been described by Berrill (I950), and his figures and description indicate a dissociation between the ampullae and epidermal vesicles. A reexamination of the larvae of this form shows that this is a false disjunction. This is most evident in the younger stages. Berrill describes (p. 46) a ring of eight ampullae, in the larva of Polyclinum, surrounding the anterior tip of the trunk, and 'numerous epidermal vesicles growing out or detached from two long strands reflected posteriorly' (p. 89).

The young larva, at the time when the yolk sac is incomplete ventrally and the atrial invaginations are just beginning (Fig. I $a$ ), already possesses fully formed sense organs and rudimentary suckers. In the epidermis there are two well-defined lateral ridges starting dorsally about one-third from the anterior end and running forward on either side of the suckers. They then run on each side of the mid-ventral line back to the base of the tail. Anteriorly these ridges swell, between and beside the suckers, to form ampullary lobe rudiments. There is no trace here of a ring of ampullae surrounding the anterior tip.

At a somewhat later stage (Fig. I $b, c$ ), when the larva is nearly fully formed, about four 'ampullae' have been developed on each side of the suckers by outgrowths from the ridges. Fartive back the lateral ampullary ridges have budded off vesicles which remain attached to the ridges by thinner or thicker necks. In the intermediate region, dorsally and ventrally, between the ampullae and the vesicles are outgrowths which might receive either nameampullae or vesicles. They are intermediate in position and size, and may be regarded as small ampullae or large vesicles. There is an even gradation from ampullae to vesicles. The arrangement at this stage is a pair of lateral ampullary ridges which start dorsally on either side of the branchial siphon, run forward and turn in a ventral direction beside the suckers; they then turn to run backwards on each side of the mid-ventral line and end with a dorsally reflected hook beside the base of the tail. These ridges bear outgrowths on short stalks, which, in the more posterior parts of the ridges are small and known as vesicles, but in the more anterior portions are large and known as ampullae. There is no morphological difference between them.

In the fully developed larva the lateral ampullary ridges are less obviousperhaps more of their tissue has entered into the formation of vesicles and 
ampullae; some of the vesicles seem to have severed their attachment to the ridge by an attenuation of the stalk, and the difference in size between the vesicles and ampullae is more pronounced, but the gradation between them is never quite obliterated.

I wish to thank the Director of the Plymouth Laboratory for facilities for research, and Miss P. Kott for her co-operation.

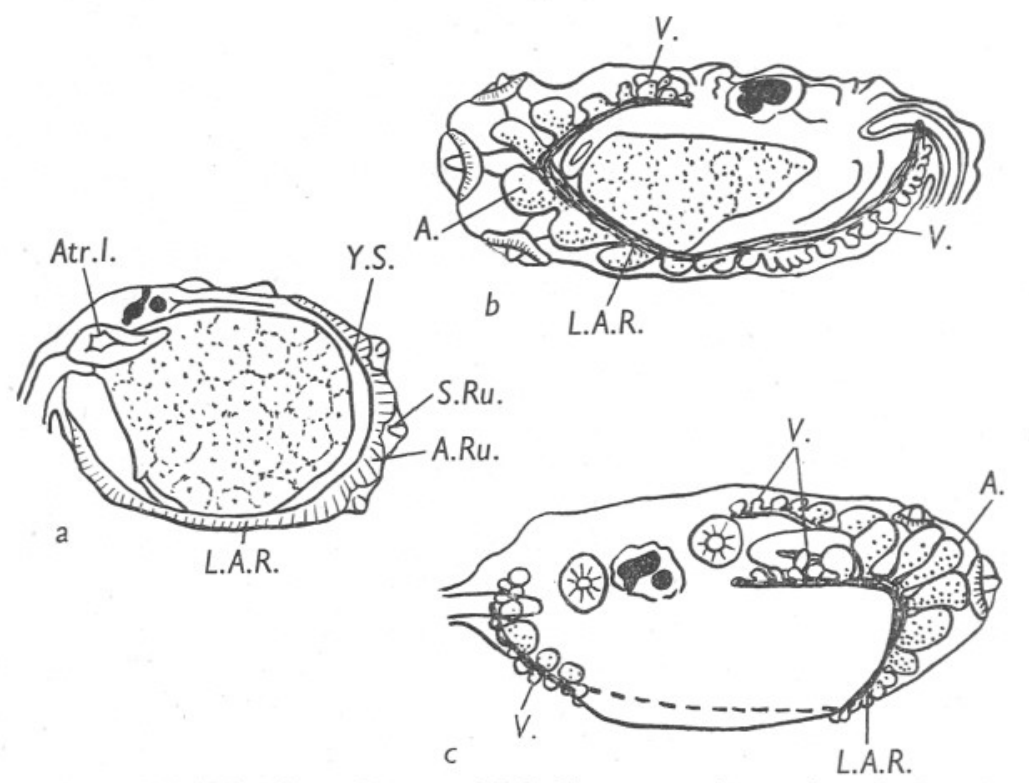

Fig. I. Camera lucida drawings of larvae of Polyclinum aurantium to show the lateral ampullary ridges. $a$, a larva at the stage when the yolk sac is incomplete ventrally, from the right side; $b$, a nearly fully formed larva, from the left side; $c$, a larva at the same stage as $b$, a dorso-lateral view from the right side. A. ampulla; $A$.Ru. rudiment of ampulla; Atr.I. atrial invagination; L.A.R. lateral ampullary ridge; S.Ru. rudiment of sucker; V. vesicle; Y.S. yolk sac.

\section{SUMMARY}

The morphology of the ampullary lobes and epidermal vesicles of the larva of Polyclinum aurantium M. Ed. (Tunicata) is described anew and the two structures are shown to be outgrowths, differing only in size and anteroposterior position, of two lateral ampullary ridges.

\section{REFERENCES}

Berrill, N. J., I950. The Tunicata. Ray Soc., Publ., No. I33. London. 354 pp. MilNe EdWARDS, H., I842. Observations sur les Ascidies composées des côtes de la Manche. Mém. Acad. Sci. Paris, T. 18, pp. 217-326. 